\title{
Evaluating Performance of Concrete Special Moment Resisting Frames with Different Seismic Coefficients Using Endurance Time Method
}

\author{
Hadi Radmanesh ${ }^{\mathrm{a}^{*}}$, Majid Mohammadi ${ }^{\mathrm{b}}$ \\ a Department of Civil Engineering, West Tehran Branch, Islamic Azad University, Tehran, Iran. \\ ${ }^{b}$ International Institute of Earthquake Engineering and Seismology, Tehran, Iran. \\ Received 19 December 2017; Accepted 25 January 2018
}

\begin{abstract}
This performance-based study was conducted to investigate the effects of seismic coefficients on performance of concrete special moment frames of 5,7, and 10-storey buildings located in Tehran, Iran. The structures are designed three-dimensionally by ETABS 2016 software according to ACI-318-08. Fifteen specimens were designed with different base shears having seismic coefficients of 0.7, 0.85, 1, 1.15, and 1.30 times the proposed value of Iranian Standard 2800, (i.e. decreased by 70 and 85\%, and increased by 115 and 130\%). Endurance time method (ETA20in series of ET acceleration function) as well as three real earthquake records was employed to evaluate the seismic performance of the modeled structures. The performance of structures was compared by the time of the first plastic hinges formation in beams and columns, the time of entering to nonlinear region and the time of experiencing storey drift of $2 \%$ corresponding to the life safety performance level. It was observed that the results of ET records and real records were similar to each other. A procedure was proposed for finding optimum structure with lower weight using ET method through defining efficient ratio (ER) and cost ratio (CR). Based on the results of ER/CR ratio and considering the importance of collapse prevention performance level, optimum structure was a 7-storey structure with lower weight or cost whose seismic coefficient had been reduced by $70 \%$. It was concluded that high safety can not be achieved simply by increasing the seismic coefficient of structures.
\end{abstract}

Keywords: Performance-Based Seismic Engineering; Seismic Coefficients; Concrete Special Moment Frames; Endurance Time Method.

\section{Introduction}

The stability of the building against earthquakes is a necessity. Many studies have been conducted on estimating the performance of structures during and after earthquakes to prevent destruction and death caused by earthquake. This valuable goal has led to the emergence of many regulations and standards aimed to advance previous rules. One of these methods has been developed by SEAOC Vision 2000 Committee in 1995 [1] called performance-based earthquake engineering where structural design criteria are expressed in terms of achieving a set of different performance levels including Collapse Prevention (CP), Life Safety (LS), or Immediate Occupancy (IO). Ordinary buildings are expected to provide less than a $2 \%$ chance over 50 years of damage of exceeding $\mathrm{CP}$ performance [2, 3]. Recently, time history $(\mathrm{TH})$ methods that generate more accuracy compared to simple methods have been developed to predict seismic behavior of structures. The standard methods although have high accuracy but due to time-consuming process, they are difficult to be used. In this regard, a new technique for time history seismic analysis of structures has been developed where the structure is subjected to accelerograms that impose increasing dynamic demand on the

* Corresponding author: radmanesh.h53@gmail.com

doi) http://dx.doi.org/10.28991/cej-030971

> This is an open access article under the CC-BY license (https://creativecommons.org/licenses/by/4.0/).

(C) Authors retain all copyrights. 
structure with time [4] . This technique is called Endurance time (ET) method. It is a dynamic pushover procedure. This seismic analysis method utilizes specific intensifying acceleration functions to analyze seismic behaviors. Using this method, it is possible to estimate the structural response at different equivalent seismic intensity levels. The use of ET method, reducing the required computational effort, allows the use of different optimization methods to determine the design parameters. Its basic concepts were introduced by Estekanchi et al [5], and its first application in linear seismic analysis was conducted by them in 2007 [6]. Currently, this method has applications in seismic assessment of various structural types and in different areas of earthquake engineering. This procedure tends to pave a way for practical performance-based design of structures [7].

Almost all of recent studies found in literature have been conducted by Iranian authors especially by Estekanchi and his colleagues. For example, Valamanesh and Estekanchi [8] proposed a procedure for three-directional seismic analysis of buildings and investigated application of ET method to several steel moment frames. The Frames were analyzed under ET acceleration functions in horizontal and vertical directions simultaneously and results were compared to response history analysis. They found out that ET method can predict the results from multi-component analysis, including vertical excitation, with reasonable accuracy. Riahi et al. [9] investigated the use of ET method in nonlinear seismic analysis of steel structures. They applied a set of three acceleration functions to various steel moment frames and the results of analysis were compared to the results of incremental dynamic analysis. It was proved that this method can be used in nonlinear analysis of structures. In a similar study, Estekanchi et al. [7] used ET method in seismic assessment of steel frames. It was shown that ET analysis can estimate the results of full response history analysis with reasonable accuracy at different excitation levels. ET analysis results are also shown to be reasonably consistent for different material models. The seismic response of unanchored steel liquid storage tanks was investigated by Alembagheri and Estekanchi [10] using the ET method and compared to responses obtained for anchored tanks under actual ground motions and intensifying ET records. It was observed that uplifting of the tank base can be predicted with reasonable accuracy by using currently available ET records. Valamanesh et al. [11] used ET method in studying seismic analysis of concrete gravity dams. For this purpose, Results from linear analysis of Folsom and Koyna dams under real earthquakes and ET acceleration functions were compared. It was shown that the ET method can predict the response of concrete gravity dams to individual earthquakes with reasonable accuracy in linear analysis. Tavazo et al. [4] proposed a procedure for linear seismic analysis of shell structures and applications of this method was investigated for several cases of shell structures. These structures were analyzed under three ET acceleration functions in one direction and the results then were compared to time history analysis considering seven actual earthquake records. The results of the ET method also were compared to response spectrum analysis method. Results revealed that the ET method predicts the linear seismic performance of shell structures with acceptable precision and significant reduction in analysis time. Basim and Estekanchi [12] studied application of ET method in value-based seismic design of structures. They introduced new design methodology based on the total value of the structure namely Value Based Design (VBD) of structures by the use of ET method. Their optimization goal was to minimize the total cost of the structure during its life span resulting in maximized value of the structure in its life time. Amouzegar and Tajmir Riahi [13] studied seismic performance of a comprehensive database of reinforced concrete moment-resisting frames using ET and time history analysis. Ground motions used in this study were spectrally matched to the design spectrum used for the generation of the input motions of ET analysis. The ET method was shown to provide an estimate of maximum inter-storey drift ratio, roof displacement and plastic hinge rotations that was very close to the results of time history analysis. According to them, this method can also correctly predict the distribution of displacement and lateral forces over all storeys. Their results reported that input motions of the ET method, generated based on a design response spectrum can be used to assess frames at different seismic hazard levels correctly. Maleki-Amin and Estekanchi [14] evaluated various damage indices of a steel moment frame at two hazard levels via nonlinear time-history analyses of the structure under scaled earthquakes and ET records. They observed that in steel moment-resisting frames, the frame damage estimation can be improved by modifying the target time of ET records based on damage spectra.

In this performance-based study we evaluated the effect of seismic coefficient variations on resistance of buildings against earthquakes. The seismic coefficients are dimensionless coefficients which represent the (maximum) earthquake acceleration as a fraction of the acceleration due to gravity. Considering the applicability of ET method in seismic analysis of concrete structures, by changing the base shear and examining its effect on three 5, 7, and 10storey structures with concrete special moment frames in Tehran, Iran, we attempted to define a procedure for finding optimum structure with lower weight or cost using ET method. We examined performance of structures with respect to the time of first plastic hinges formation in beams and columns, and time of entering to nonlinear region as well as inter-story and residual drifts of nine ET records and three real earthquake records.

\section{Concept Of Endurance Time Method}

In ET method, the main structural responses such as displacement, storey shift, tension, force, stress, rotation of plastic joints, and other related parameters during the analysis are measured. The structural responses are illustrated 
against time (intensity) and are evaluated based on damage levels corresponding to various equivalent excitation intensities. The time and damage indexes (performance measures) are the key factors in this method. The performance of a structure is evaluated based on the time when the damage limit index is exceeded [5]. In ET method, it is assumed that three structures are on the shaking table. Then the table is subjected to a random vibration whose intensity increases gradually. At the start of experiment, all structures are stable. Then, experiment begins by imposing an intensifying ET acceleration function. It is observed that up to 5th second (for example), the vibration intensity of the table is low and all the structures are stable. At 5th second, Frame 2, and then at 15th second Frame 1 and finally at 20th second Frame 3 are collapsed. So, it can be concluded that Frame 2 that has weaker performance (with lowest endurance time) and Frame 3 has stronger performance among studied structures which would be more resistant against seismic excitation compared to Frame 1.

The methodology of ET method is summarized in Figure 1. The most important component of ET method is ET acceleration functions: "ET excitation functions are in the form of artificial accelerograms created in such a way that each time window of them from zero to a particular time produces a response spectrum that matches a template spectrum with an increasing scale factor" [12]. The ET accelerogram is created so that at a predefined time ( $\left.\mathrm{t}_{\text {Target }}\right)$ its response spectrum reaches a pre-specified template response spectrum. The results of the ET method are usually interpreted by a curve called "ET Response/ Performance Curve". The target response of ET acceleration functions are defined as:

$S_{a T}(T . t)=\frac{t}{t_{\text {Target }}} S_{a c}(T)$

$S_{u T}(T . t)=\frac{t}{t_{\text {Target }}} S_{a c}(T) \times \frac{T^{2}}{4 \pi^{2}}$

Where $S_{\mathrm{aT}}(\mathrm{T}, \mathrm{t})$ is the target acceleration response at time $t$, $\mathrm{T}$ is the period of free vibration, $\mathrm{S}_{\mathrm{ac}}(\mathrm{T})$ is the codified design acceleration spectrum, and $\mathrm{S}_{\mathrm{uT}}(\mathrm{T}, \mathrm{t})$ is the target displacement response at time $\mathrm{t}$.

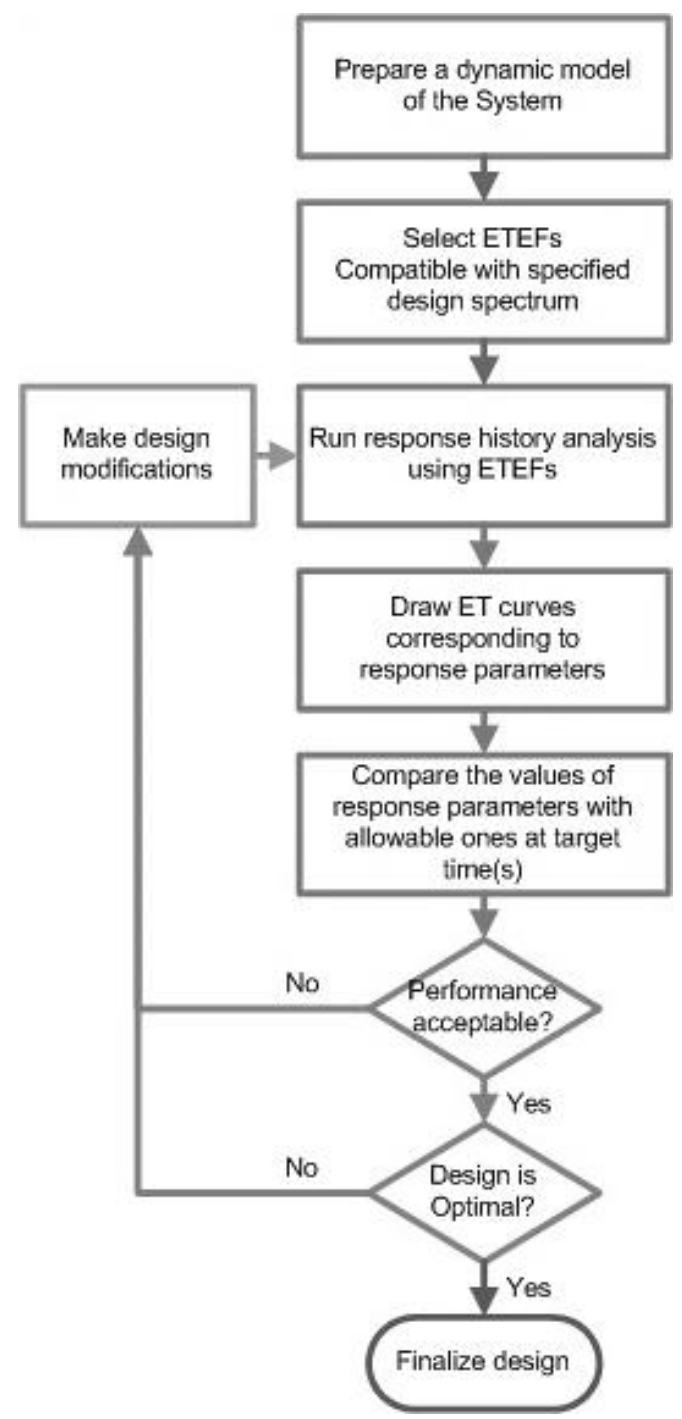

Figure 1. Algorithm of ET method 


\section{Research Methodology}

\subsection{Structures, Specimens, Reinforcement, And Materials}

The studied structures are three concrete special moment frames with 5, 7, and 10 storeys located in Tehran, Iran on soil type $\mathrm{C}$ conditions which were three-dimensionally modeled and designed using ETABS 2016 software according to seismic loading requirements of ACI-318-08 (see Figure 2). Their geometries are similar to each other having three spans of 5, 6, and $5 \mathrm{~m}$ and a floor height of $3 \mathrm{~m}$. Design of special moment frames was according to Iranian Code of Practice for Seismic Resistant Design of Buildings (Standard 2800) using spectral analysis technique. Their importance factor (I), design base acceleration (A), and reflection coefficient (B) were set as 0.35 , 1, and 1.288, respectively. Also, their behavior factor $(\mathrm{R})$ was considered as 7.5 according to Standard 2800 with a damping ratio of $5 \%$. In this regard, Seismic coefficients (C) for these structures were then obtained as 0.0851 for 5-sorey, 0.0657 for 7 storey, and 0.0537 for 10-storey frames. For all structures, story live load, story dead load, roof live load, partition load, and roof snow load are 200,350,150,100, and $126 \mathrm{~kg} / \mathrm{m}^{2}$, respectively.

Due to the use of spectral analysis technique, response-spectrum base shear was matched with $85 \%$ of the static base shear. The initial base shear of the structures was calculated in accordance with the fourth edition of Standard 2800. Then, test specimens were generated with different base shears having seismic coefficients of $0.7,0.85,1,1.15$, and 1.30 times the proposed value of Standard $2800(0.7 \mathrm{C}, 0.85 \mathrm{C}, 1 \mathrm{C}, 1.15 \mathrm{C}$, and $1.30 \mathrm{C})$. This was done to examine different structural behavior in a broad nonlinear range. The design base acceleration (A) for these structures was calculated as $0.245,0.2975,0.35,0.4025$, and 0.455 for those with $0.7 \mathrm{C}, 0.85 \mathrm{C}, 1 \mathrm{C}, 1.15 \mathrm{C}$, and $1.30 \mathrm{C}$ seismic coefficients, respectively. Table 1. presents the specifications of these specimens. Since design base acceleration of Tehran is equal to $0.35 \mathrm{~g}$, it was considered as a basis for comparing the optimality of structures.

Compressive strength of the used concrete is $300 \mathrm{~kg} / \mathrm{cm}^{2}$ and its Modulus of elasticity is $2.61 \times 10^{5} \mathrm{~kg} / \mathrm{cm}^{2}$. For reinforcement, 16-mm steel rebars were employed where Modulus of elasticity was $2 \times 10^{6} \mathrm{~kg} / \mathrm{cm}^{2}$. The longitudinal steel reinforcements (A-III class) have a yield strength of $4000 \mathrm{~kg} / \mathrm{cm}^{2}$ and ultimate strength of $6000 \mathrm{~kg} / \mathrm{cm}^{2}, \mathrm{while}$ for transverse reinforcement (A-II class), they were 3000 and $4500 \mathrm{~kg} / \mathrm{cm}^{2}$, respectively. Modeling the non-liner behavior of concrete and steel materials was conducted by using hysteresis curves. In this regard, Kinematic hysteresis model was used for steel modeling. It is based on kinematic hardening behavior and is the default hysteresis model for all metal materials. Upon unloading and reverse loading, the curve follows a path made of segments parallel to and of the same length as the previously loaded segments and their opposite-direction counterparts until it rejoins the backbone curve when loading in the opposite direction. This behavior is illustrated in Figure 3. Takeda hysteresis model also was employed for concrete modeling according to the software guide recommendation. This model was proposed by Takeda et al. [15]. It is very similar to the kinematic model, but uses a degrading hysteretic loop. Unloading is along the elastic segments similar to the kinematic model. When reloading, the curve follows a secant line to the backbone curve for loading in the opposite direction. The target point for this secant is at the maximum deformation that occurred in that direction under previous load cycles. This results in a decreasing amount of energy dissipation with larger deformations. The behavior is shown in Figure 4. This model is often used in a storey-based earthquake response analysis. For more information, see Reference [15]

Table 1. Specifications of specimens

\begin{tabular}{|c|c|c|c|c|}
\hline Structures & Seismic coefficient & Structure weight (ton) & Weight ratio & base shear (ton) \\
\hline \multirow{5}{*}{ 5-storey } & $0.7 \mathrm{C}$ & 276.6 & 0.879 & 61.1 \\
\hline & $0.85 \mathrm{C}$ & 295 & 0.938 & 76 \\
\hline & $1 \mathrm{C}$ & 314.45 & 1 & 91 \\
\hline & $1.15 \mathrm{C}$ & 341.45 & 1.085 & 106.73 \\
\hline & $1.3 \mathrm{C}$ & 370.55 & 1.178 & 123 \\
\hline \multirow{5}{*}{ 7-storey } & $0.7 \mathrm{C}$ & 433.5 & 0.814 & 67.57 \\
\hline & $0.85 \mathrm{C}$ & 507.55 & 0.953 & 89 \\
\hline & $1 \mathrm{C}$ & 532.2 & 1 & 105.64 \\
\hline & $1.15 \mathrm{C}$ & 591.6 & 1.111 & 123.61 \\
\hline & $1.3 \mathrm{C}$ & 628.6 & 1.181 & 145.07 \\
\hline \multirow{5}{*}{ 10-storey } & $0.7 \mathrm{C}$ & 736.2 & 0.881 & 76.94 \\
\hline & $0.85 \mathrm{C}$ & 772.3 & 0.925 & 101.15 \\
\hline & $1 \mathrm{C}$ & 834.8 & 1 & 121.72 \\
\hline & $1.15 \mathrm{C}$ & 877.4 & 1.051 & 138.64 \\
\hline & $1.3 \mathrm{C}$ & 971.8 & 1.164 & 166.8 \\
\hline
\end{tabular}



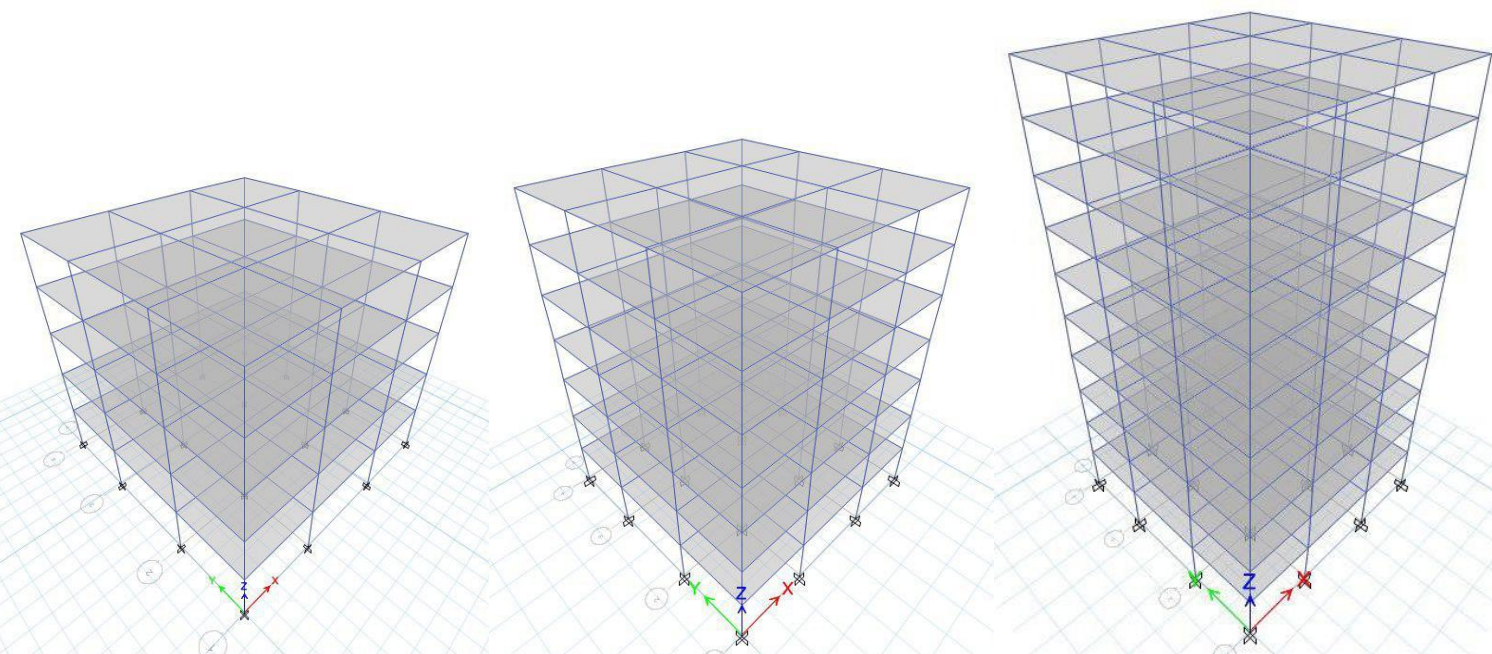

Figure 2. 3D models of 5, 7, and 10- storey structures

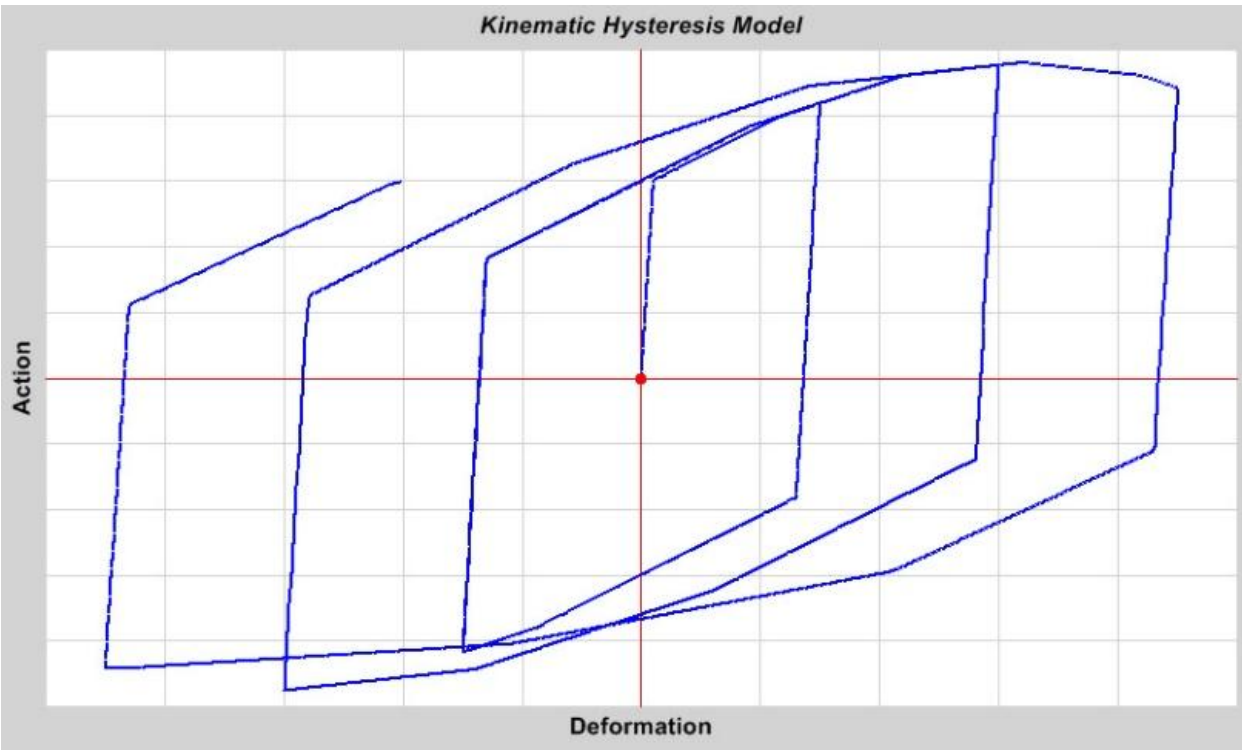

Figure 3. Kinematic hysteresis model

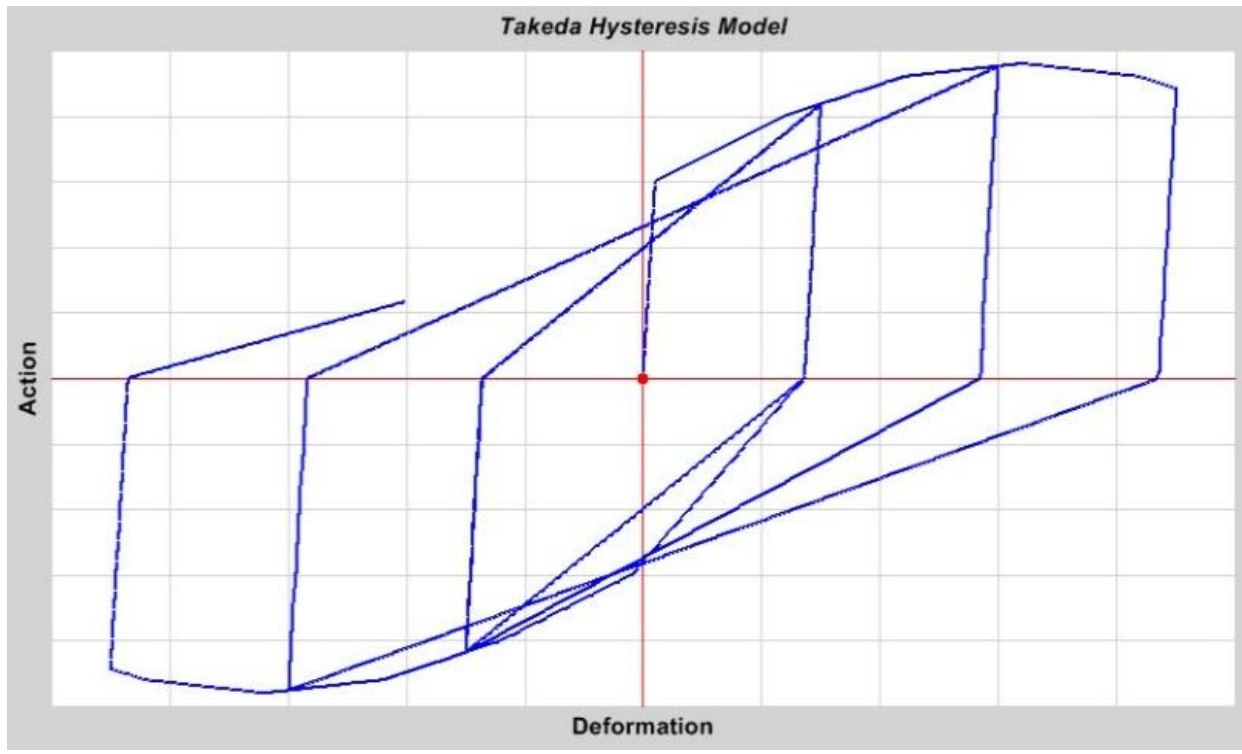

Figure 4. Takeda hysteresis model 


\subsection{Time history records}

In addition to ET records (see Section 3.3), in this study we extracted ground motion records of the earthquakes of Chi-Chi (Taiwan, 1999) with PGA=0.47 and $\mathrm{M}$ (magnitude) $=7.62$, Kobe (Japan, 1995; PGA=0.48 and M = 7.13), and Hector Mine (southern California, 1999; PGA=0.32 and $\mathrm{M}=6.9$ ) from Pacific Earthquake Engineering Research Center (PEER) ground motion database for soil type $\mathrm{C}$ condition. Figure 5. presents acceleration functions of real records. Scale factors of these real records for 5, 7, and 10 storey structures were obtained as $1.65,1.71$, and 2.31 based on the design base acceleration of Tehran $(A=0.35 \mathrm{~g})$ and their SRSS. After matching ET records with real records, they were applied to linearly designed structures three times, and then their inter-story and residual drifts were measured and their results, in addition to ET results, were used for determining the structure with best performance.

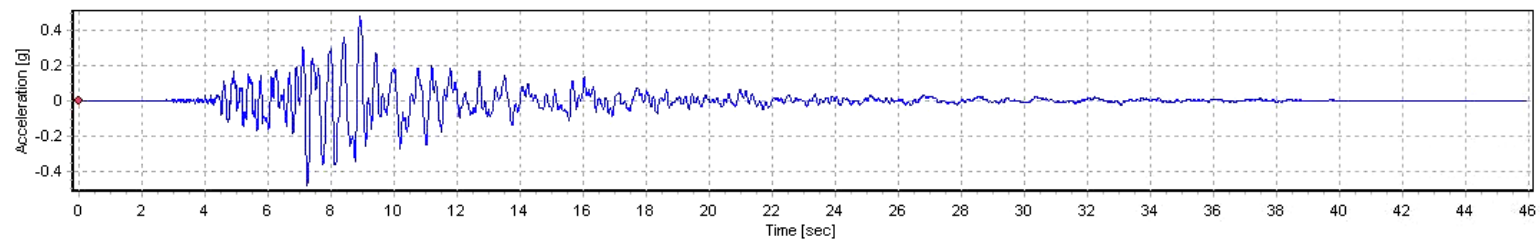

(a) Kobe earthquake

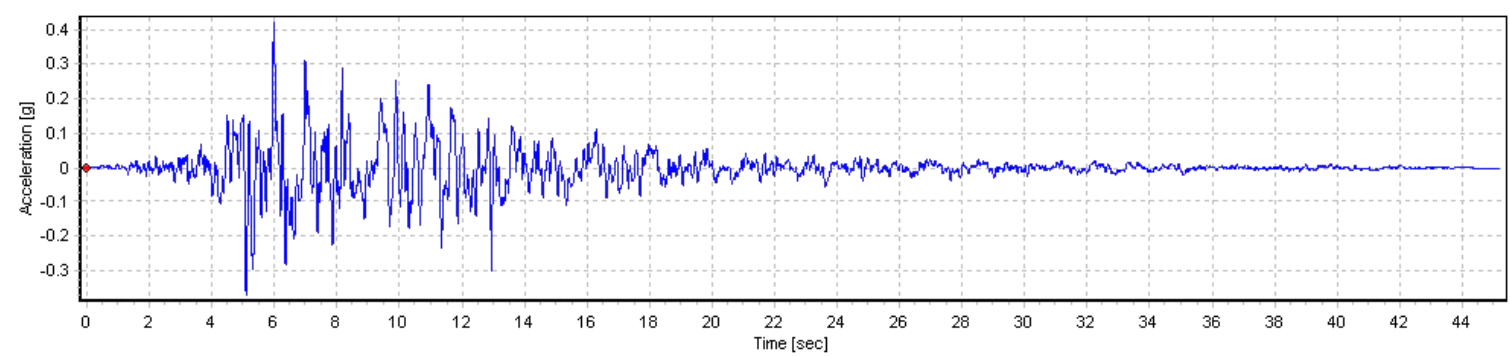

(b) Hector Mine earthquake

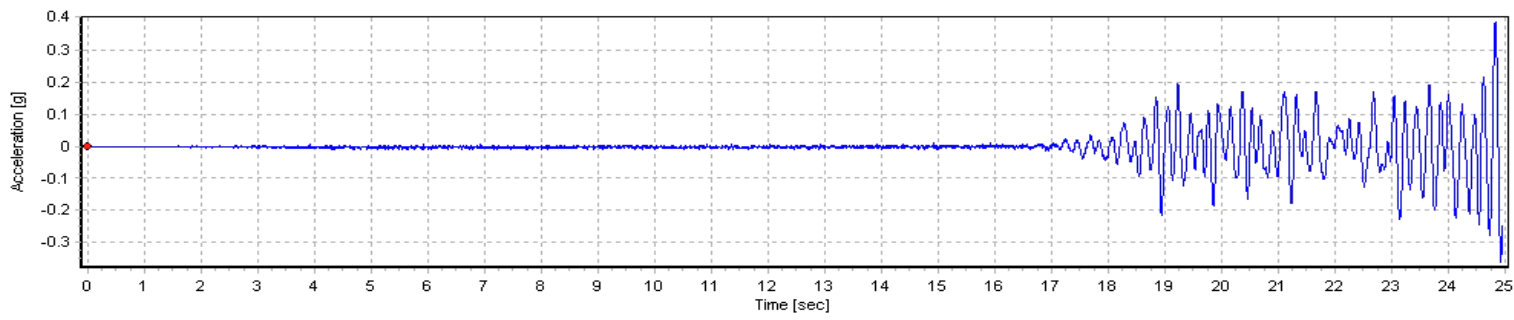

(c) Chi-Chi earthquake

Figure 5. Acceleration functions of real records

\subsection{Application of ET method in nonlinear analysis}

For the analysis of structures with ET method, acceleration functions of ETA20in series of ET acceleration function (ETAF) were used based on the soil type C presented in FEMA 440 [16]; these sets are named as ETA20inx01-3, ETA20iny01-3, and ETA20inz01-3 (9 accelerograms). They have an endurance time of $20 \mathrm{~s}$ and their code spectrum is based on Standard 2800. They also support nonlinear ranges. Figure 6. presents acceleration functions of ETA20in01 accelerograms, as a sample. The target time was set to $t=10 \mathrm{~s}$ according to Standard 2800. ET acceleration functions considered in this study were calibrated in such a way that their response spectra only match that of the template code spectra at $10 \mathrm{~s}$.

In order to be in agreement with the seismic codes, each of ET functions was scaled. To do so, it was supposed that the average SRSS spectrum for all EA accelerograms should not fall below 1.3 times the Standard 2008 spectrum for a period of 0.2T-1.5T ( $\mathrm{T}=$ Main period of vibration for each frame). Figure 7. presents comparison between SRSS spectrum of ETA20iny01 and Standard 2008 spectrum, as a sample. 


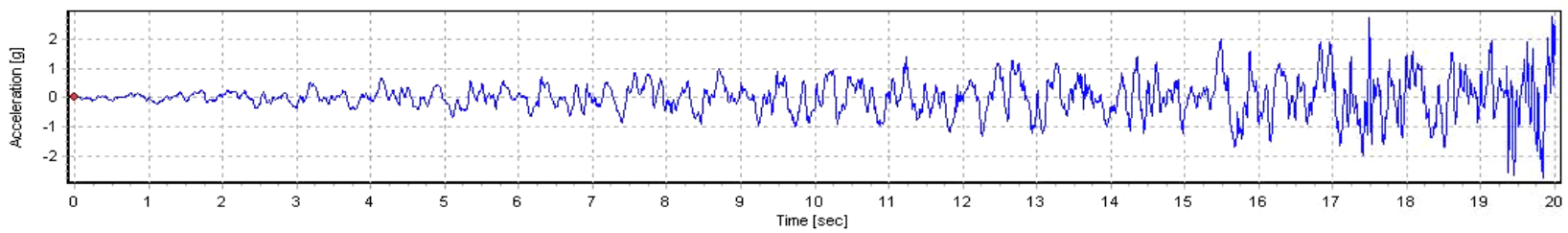

(a) ETA20inx01

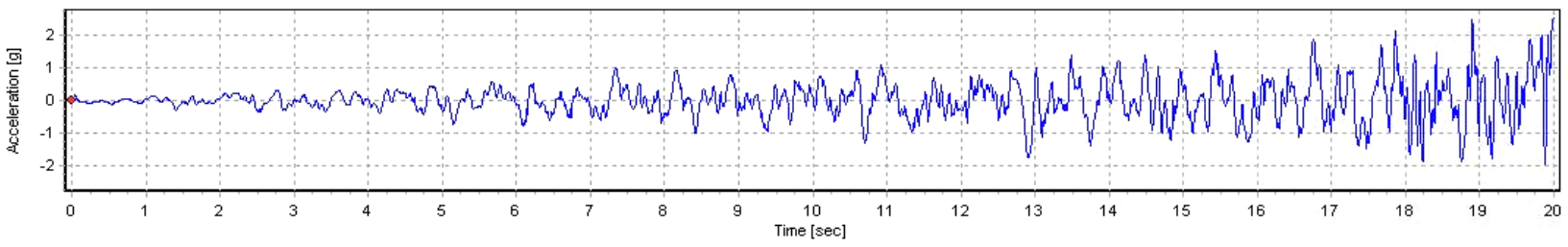

(b) ETA20iny01

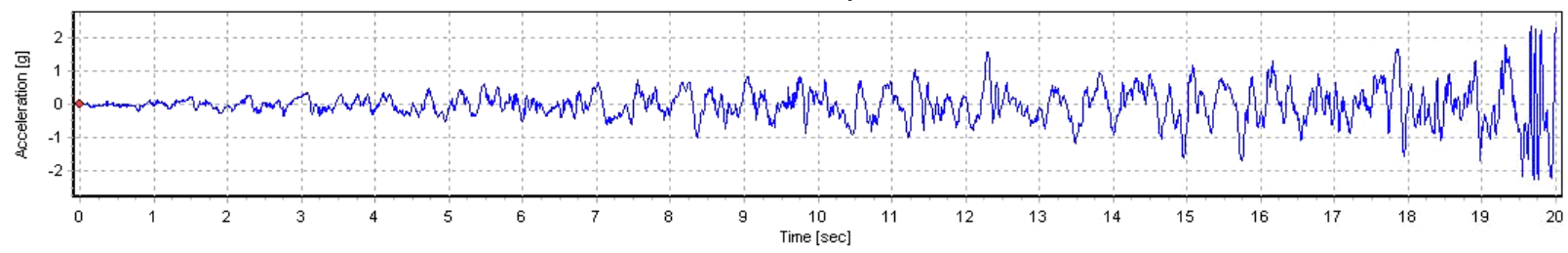

(c) ETA20inz01

Figure 6. Acceleration functions of the ETA20in01
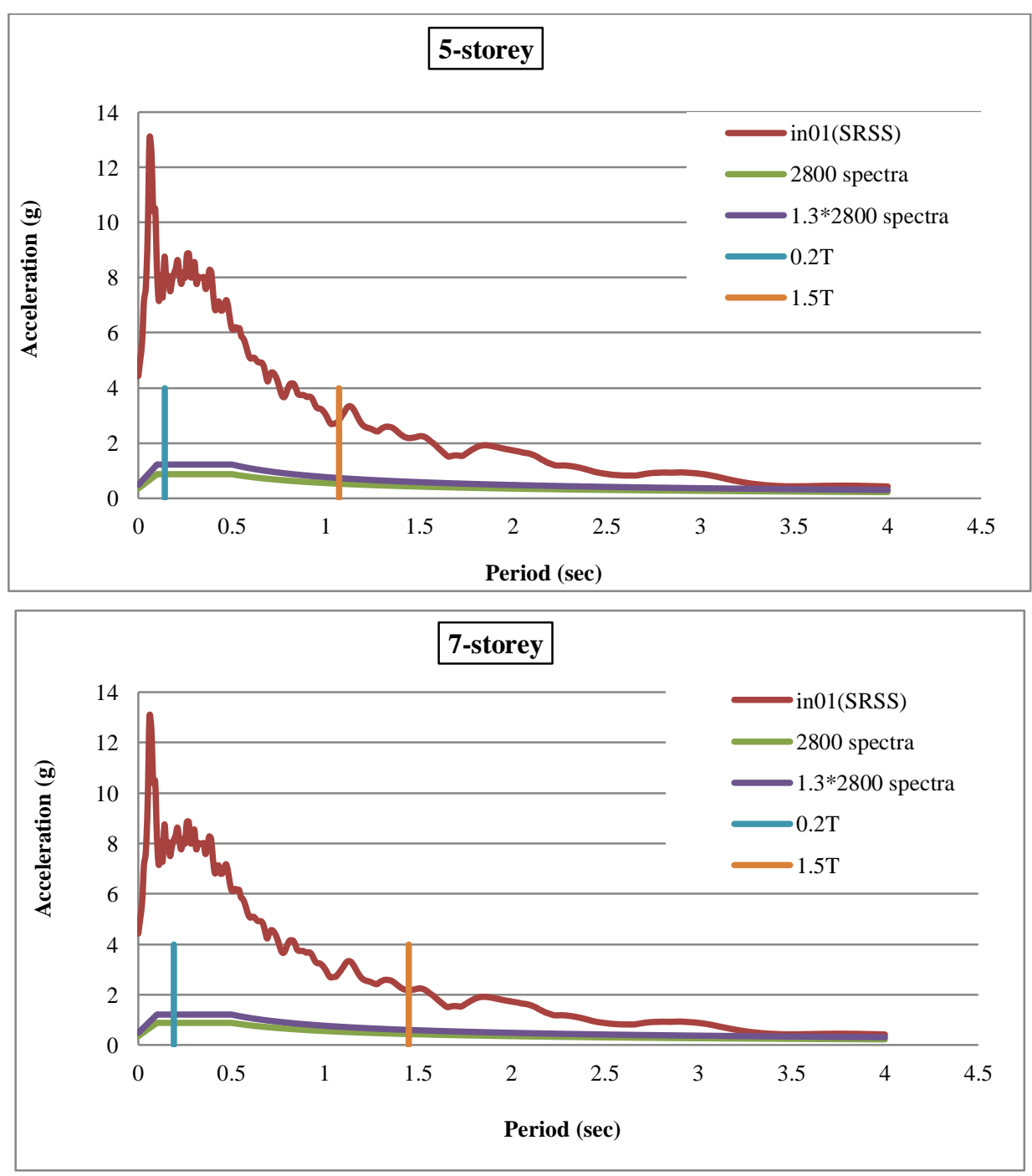


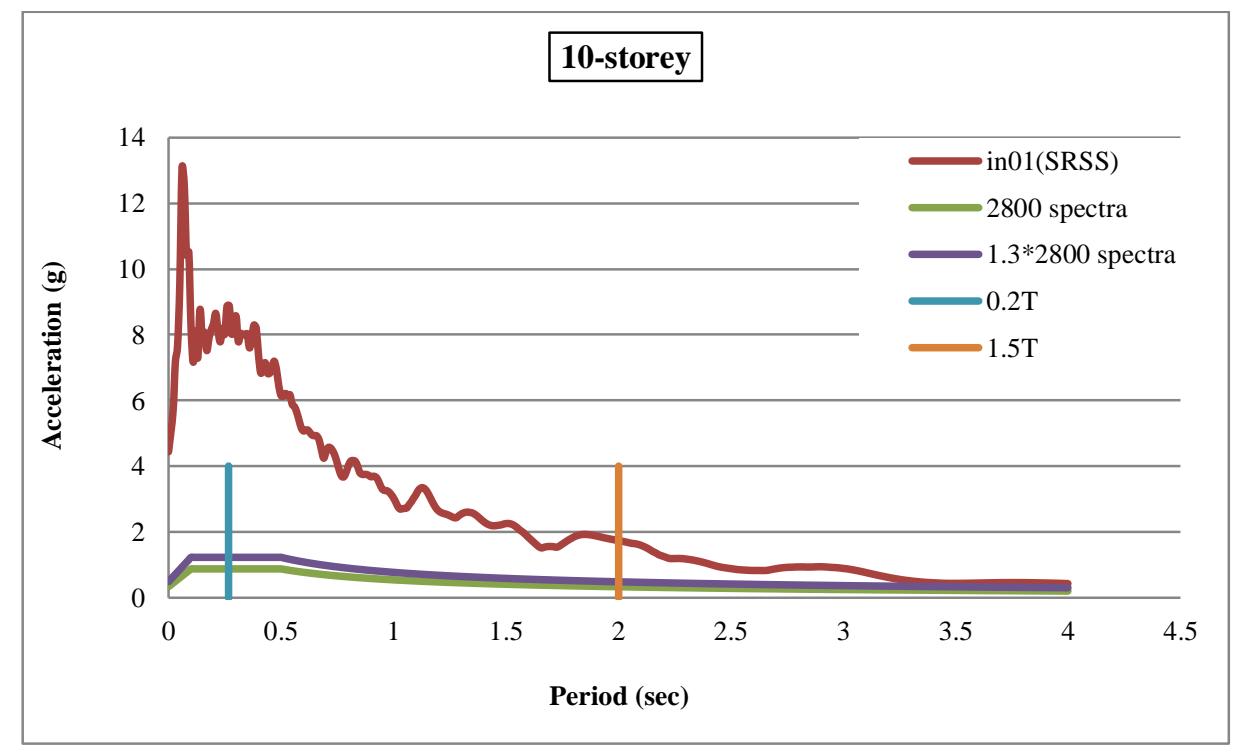

Figure 7. Comparison between SRSS spectrum of ETA20iny01 and Standard 2008 spectrum

\section{Results}

In this section we compared endurance time of structures after subjecting them to ET records based on the time of first plastic hinges formation and the time of entering to nonlinear region as well as their inter-story and residual drifts. In addition, maximum inter-story and residual drift results of structures under real earthquake records were evaluated. Based on total results, the best structure with lower weight or cost was determined.

\subsection{Structures with Better Performance Based on the Time of First Plastic Hinges Formation}

According to the time of plastic hinges formation in beams and columns of structures shown in Table 2, it was reported that 5 -story with $1.15 \mathrm{C}, 7$-storey with $0.7 \mathrm{C}$, and 10 -storey with $1 \mathrm{C}$ had better seismic performance at IO-LS level compared to other structures. At LS-CP level, 5-story with 0.85C, 7-storey with 1.3C, and 10-storey structures with $0.85 \mathrm{C}$ showed greater performance. Also, 5-story with $0.7 \mathrm{C}$, 7 -storey with $1.3 \mathrm{C}$, and 10 -storey with $0.85 \mathrm{C}$ structures were reported as having better performance at $\mathrm{CP}$ level.

Table 2. Time of first plastic hinge formation in beams and columns of specimens

\begin{tabular}{|c|c|c|c|c|c|c|c|}
\hline \multirow{3}{*}{ Structure } & \multirow{3}{*}{ Seismic coefficient } & \multicolumn{6}{|c|}{ Time of first plastic hinge formation (s) } \\
\hline & & \multicolumn{3}{|c|}{ Beam } & \multicolumn{3}{|c|}{ Column } \\
\hline & & $(\mathrm{IO}-\mathrm{LS})$ & $(\mathrm{LS}-\mathrm{CP})$ & $(\mathrm{CP})$ & $(\mathrm{IO}-\mathrm{LS})$ & $(\mathrm{LS}-\mathrm{CP})$ & $(\mathrm{CP})$ \\
\hline \multirow{5}{*}{5 -storey } & $0.70 \mathrm{C}$ & 1.79 & 5.43 & 7.1 & 3.13 & 7.19 & 17.25 \\
\hline & $0.85 \mathrm{C}$ & 1.87 & 5.43 & 10.16 & 3.21 & 11.45 & 13.13 \\
\hline & $1 \mathrm{C}$ & 2.32 & 5.44 & 10.17 & 3.16 & 10.9 & 11.32 \\
\hline & $1.15 \mathrm{C}$ & 2.27 & 5.46 & 10.27 & 4.78 & 10.35 & 12.22 \\
\hline & $1.30 \mathrm{C}$ & 2.25 & 6.1 & 10.37 & 4.1 & 10.95 & 12.98 \\
\hline \multirow{5}{*}{ 7-storey } & $0.70 \mathrm{C}$ & 1.85 & 5.27 & 7.23 & 5.36 & 11.98 & 12.17 \\
\hline & $0.85 \mathrm{C}$ & 1.79 & 5.4 & 11.4 & 4.84 & 12.19 & 12.46 \\
\hline & $1 \mathrm{C}$ & 2.65 & 5.42 & 12.36 & 4.81 & 12.68 & 14.58 \\
\hline & $1.15 \mathrm{C}$ & 2.36 & 6.98 & 10.67 & 4.51 & 12.23 & 13.65 \\
\hline & $1.30 \mathrm{C}$ & 2.39 & 6.22 & 12.86 & 3.19 & 17.19 & 17.36 \\
\hline \multirow{5}{*}{10 -storey } & $0.70 \mathrm{C}$ & 2.06 & 5.13 & 8.52 & 2.44 & 13.55 & 16.08 \\
\hline & $0.85 \mathrm{C}$ & 2.03 & 5.37 & 8.96 & 4.33 & 16.15 & 17.4 \\
\hline & $1 \mathrm{C}$ & 2.31 & 7.27 & 12.28 & 4.77 & 13.7 & 13.9 \\
\hline & $1.15 \mathrm{C}$ & 2.34 & 7.1 & 12.17 & 2.48 & 12.45 & 12.54 \\
\hline & $1.30 \mathrm{C}$ & 2.42 & 7.04 & 12.24 & 3.21 & 10.57 & 12.49 \\
\hline
\end{tabular}

\subsection{Structures with Better Performance Based on the Time Of Entering to Nonlinear Region}

From the results presented in Table 3, it was found that the 5-storey structure with $0.85 \mathrm{C}$ had better performance compared to other 5-storey structures when the beams and columns enter to nonlinear region and forming first plastic hinge. In 7-storey structure, the endurance time in beams was higher in the structure with $1.30 \mathrm{C}$, and those with $0.7 \mathrm{C}$ and $0.85 \mathrm{C}$ had almost same endurance times, but considering the values of the columns and their entrance to the nonlinear region as well as importance of columns relative to beams, it can be said that the 7-storey structure with $0.7 \mathrm{C}$ 
had better performance compared to others. Similar to 7 -storey structure, 10-storey structure with $0.7 \mathrm{C}$ showed stronger performance.

Table 3. Time of entering to nonlinear region in beams and columns of specimens

\begin{tabular}{cccc}
\hline \multirow{2}{*}{ Structure } & Seismic coefficient & \multicolumn{2}{c}{ Time of entering to nonlinear region (s) } \\
\cline { 3 - 4 } & & Beam & Column \\
\hline \multirow{5}{*}{ 5-storey } & $0.70 \mathrm{C}$ & 0.67 & 1.56 \\
& $0.85 \mathrm{C}$ & 0.76 & 1.58 \\
& $1 \mathrm{C}$ & 0.67 & 1.56 \\
& $1.15 \mathrm{C}$ & 1.06 & 1.58 \\
& $1.30 \mathrm{C}$ & 1.03 & 1.57 \\
\hline \multirow{3}{*}{ 7-storey } & $0.70 \mathrm{C}$ & 0.74 & 1.79 \\
& $0.85 \mathrm{C}$ & 0.7 & 1.62 \\
& $1 \mathrm{C}$ & 0.88 & 1.5 \\
& $1.15 \mathrm{C}$ & 0.88 & 1.54 \\
\multirow{3}{*}{10 -storey } & $1.30 \mathrm{C}$ & 1.03 & 1.54 \\
& $0.70 \mathrm{C}$ & 0.64 & 1.73 \\
& $0.85 \mathrm{C}$ & 0.67 & 1.67 \\
& $1 \mathrm{C}$ & 0.68 & 1.7 \\
& $1.15 \mathrm{C}$ & 0.81 & 1.57 \\
\hline
\end{tabular}

\subsection{Structures with Better Performance Based on Inter-Story Drift Ratio}

According to FEMA 356 [17], the typical suggested values of inter-story drifts are $1 \%$ for IO performance level, $2 \%$ for LS performance level and $4 \%$ for CP performance level for concrete frame structures. After subjecting to ET records, endurance time of structures at three performance levels considering the global acceptance criteria of interstory drifts were measured and presented in Table 4 . Among 5-storey structures, at IO performance level and $1 \%$ interstory drift (ID), the one with $0.7 \mathrm{C}$ had higher endurance time (7.78s). At LS level with $2 \% \mathrm{ID}$, structures with $1 \mathrm{C}$ and $1.15 \mathrm{C}$ showed higher endurance time, but considering the structural weight, 5 -storey with $1 \mathrm{C}$ revealed stronger performance (endurance time $=16 \mathrm{~s}$ ). Also, at $\mathrm{CP}$ level with $4 \% \mathrm{ID}$, results indicated that the structure with $1.3 \mathrm{C}$ had higher endurance time (21.66s) and hence, had better performance.

Among 7-storey structures, the one with $1 \mathrm{C}$ showed better performance at IO level and $1 \% \mathrm{ID}$ (endurance time $=$ 13.37s). At LS level and $2 \% \mathrm{ID}$, structures with $0.85 \mathrm{C}$ and $1.3 \mathrm{C}$ had higher endurance time, but considering the structure weight, $0.85 \mathrm{C}$ had stronger performance (endurance time $=15.75 \mathrm{~s}$ ). At $\mathrm{CP}$ level and $4 \% \mathrm{ID}, 1.15 \mathrm{C}$ showed stronger performance by considering the weight of structure (endurance time $=23.44 \mathrm{~s}$ ).

Finally, results for 10-storey structures revealed that $1.3 \mathrm{C}$ with an endurance time of $7 \mathrm{~s}$ had better performance at IO level and $1 \%$ ID, while at LS level and $2 \%$ ID, $1.15 \mathrm{C}$ showed better performance by considering the weight of structure (endurance time $=8.5 \mathrm{~s}$ ). At CP level and $4 \% \mathrm{ID}, 1 \mathrm{C}$ showed better performance (endurance time $=18.65 \mathrm{~s}$ ) with respect to its weight which is lower than that of $1.15 \mathrm{C}$ and $1.3 \mathrm{C}$.

Table 4. Endurance time of specimens considering inter-story drift criteria for performance levels

\begin{tabular}{ccccc}
\hline \multirow{2}{*}{ Structure } & \multirow{2}{*}{ Seismic coefficient } & \multicolumn{3}{c}{ Endurance time (s) } \\
\cline { 2 - 5 } & & IO - 1\% ID & LS - 2\% ID & CP - 4\% ID \\
\hline \multirow{5}{*}{ 5-storey } & $0.70 \mathrm{C}$ & 7.78 & 10.34 & 13.71 \\
& $0.85 \mathrm{C}$ & 4.3 & 12.66 & 14.73 \\
& $1 \mathrm{C}$ & 6.04 & 16.05 & 19.18 \\
& $1.15 \mathrm{C}$ & 4.63 & 16.42 & 16.76 \\
7 7-storey & $1.30 \mathrm{C}$ & 5.36 & 13.43 & 21.66 \\
\hline \multirow{5}{*}{10 -storey } & $0.70 \mathrm{C}$ & 2.46 & 9.59 & 19.24 \\
& $0.85 \mathrm{C}$ & 5.4 & 15.75 & 21.87 \\
& $1 \mathrm{C}$ & 13.37 & 15 & 21.47 \\
& $1.15 \mathrm{C}$ & 9.24 & 13.31 & 23.44 \\
& $1.30 \mathrm{C}$ & 7.96 & 17.49 & 23.81 \\
\hline & $0.70 \mathrm{C}$ & 2.91 & 5.07 & 8.34 \\
& $0.85 \mathrm{C}$ & 2.86 & 4.3 & 10.4 \\
& $1 \mathrm{C}$ & 2.25 & 7.26 & 18.65 \\
& $1.15 \mathrm{C}$ & 4.59 & 8.5 & 18.86 \\
& $1.30 \mathrm{C}$ & 7.09 & 9.65 & 20.01 \\
\hline
\end{tabular}




\subsection{Structures with Better Performance Based on Residual Drift}

Residual drift (RD) of structures resulted from subjecting to ET records are presented in Figure 8. Results showed that 5-storey frame with $1.3 \mathrm{C}$ seismic coefficient, 7-storey frame with $0.85 \mathrm{C}$ seismic coefficient (considering its lower weight compared to 1.3C), and 10-storey with 1.3C seismic coefficient (considering its lower weight compared to $1.15 \mathrm{C}$ ) had the best performance among specimens, since they had the lowest RD ratios of 13, 24, and 14\%, respectively.

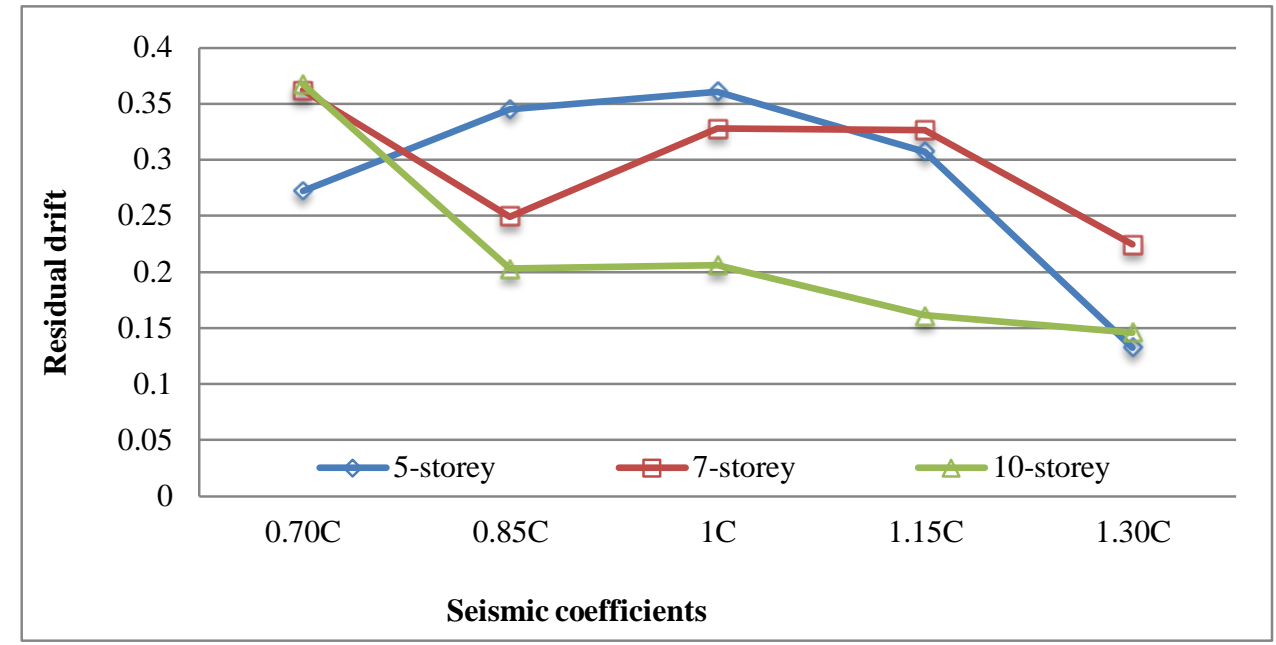

Figure 8. Residual drift results of specimens under ET records

4.5. Structures with Better Performance Based on Residual and Maximum Inter-Story Drifts under Real Records

Residual and inter-story drifts results of structures affected by real records are presented in Table 5. and Figure 8 , respectively. They revealed that among 5-storey frames, the specimen with $1.15 \mathrm{C}$ had better performance since it had the lowest RD $(0.66 \%)$ and maximum ID $(0.71 \%)$. Among 7-storey frames, $0.7 \mathrm{C}$ showed better performance with RD ratio of $0.71 \%$ and maximum ID ratio of $0.68 \%$. Also, results of 10 -storey frames indicated that the specimens with $0.7 \mathrm{C}$ and $1.15 \mathrm{C}$ had good performance but by considering the lower weight of the specimen $0.7 \mathrm{C}$ compared to $1.15 \mathrm{C}$, it was found out that $0.7 \mathrm{C}$ had the best performance against real earthquake records, although its $\mathrm{RD}$ was higher $(\mathrm{RD}=$ $0.12 \%$, maximum ID $=0.11 \%$ ).

Results shown in Figure 8, indicated that at 5-storey structures, maximum ID was recorded at the third floor where it was found out that by increasing the seismic coefficient proposed by Standard 2800 as $115 \%$ better performance could be obtained under real earthquakes. At 7 and 10-storey structures maximum ID was observed the sixth floor in which better performance could be obtained when the seismic coefficient was reduced by $70 \%$.

Table 5. Residual drifts of specimens resulted under real records

\begin{tabular}{ccc}
\hline Structure & Seismic coefficient & RD \\
\hline $0.70 \mathrm{C}$ & 0.0095 \\
$0.85 \mathrm{C}$ & 0.0079 \\
5-storey & $1 \mathrm{C}$ & 0.0079 \\
& $1.15 \mathrm{C}$ & 0.0066 \\
$1.30 \mathrm{C}$ & 0.0077 \\
\hline 7-storey & $0.70 \mathrm{C}$ & 0.0071 \\
& $0.85 \mathrm{C}$ & 0.0085 \\
$1 \mathrm{C}$ & 0.0080 \\
& $1.15 \mathrm{C}$ & 0.0089 \\
& $1.30 \mathrm{C}$ & 0.0090 \\
\hline $0.70 \mathrm{C}$ & 0.0121 \\
& $0.85 \mathrm{C}$ & 0.01619 \\
$10-$ storey & $1 \mathrm{C}$ & 0.0154 \\
& $1.15 \mathrm{C}$ & 0.0111 \\
& $1.30 \mathrm{C}$ & 0.0103 \\
\hline & & \\
\hline
\end{tabular}



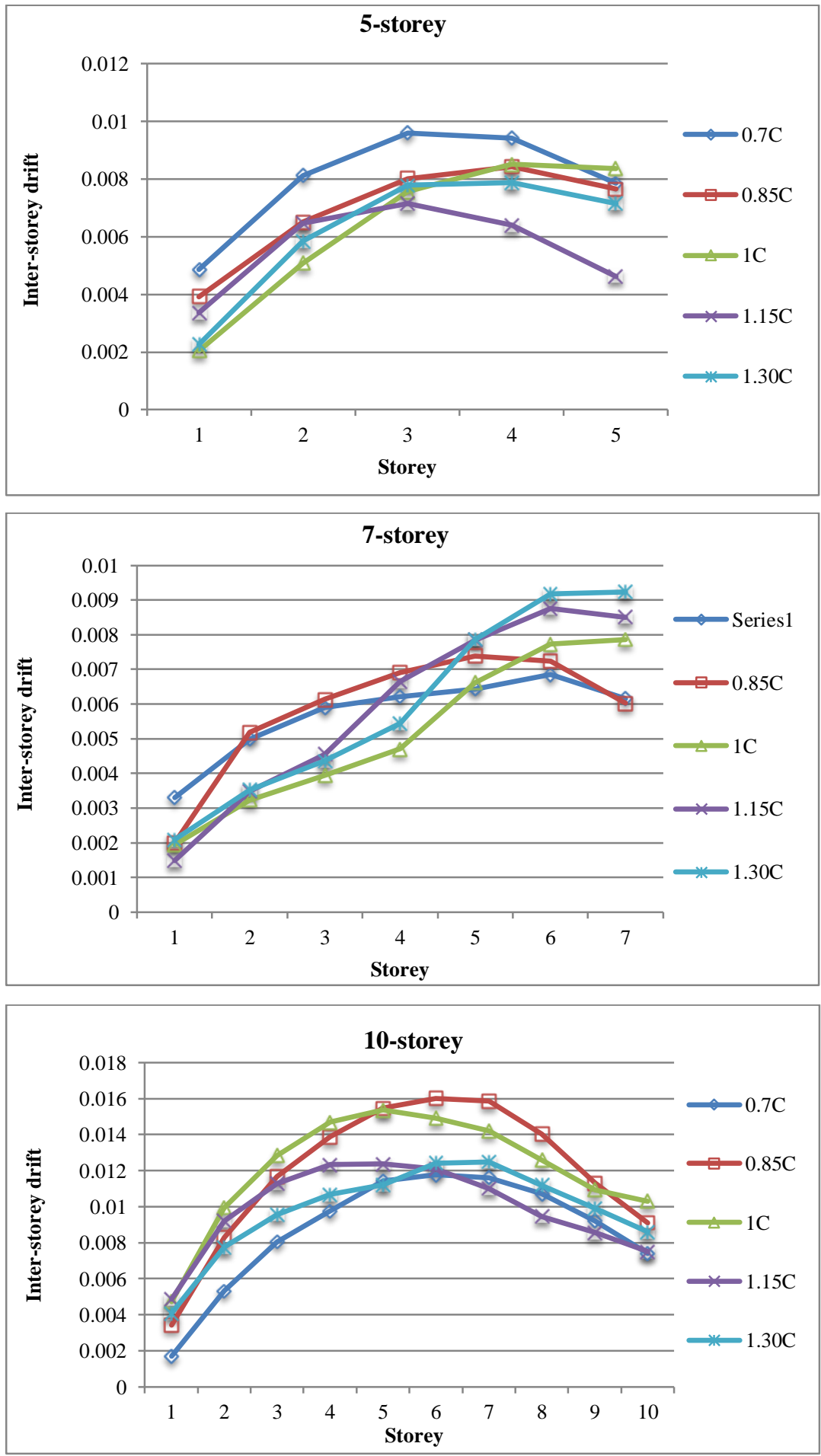

Figure 9. Maximum inter-story drift results of specimens under real records

\subsection{Determining Optimum Structure}

For determining optimum structure by the means of ET and real records, first we defined Cost Ratio (CR) and Efficient Ratio (ER). For both methods, CR can be obtained from dividing the weight of specimens into the weight of modeled structures (i.e. those with 1C). For calculating ER using ET method, we can divide the endurance time of specimens into the endurance time of modeled structures. Now, by dividing ER into CR we can define a criterion for finding the optimum structure based on ET records.

Their results for three performance levels by using ET method are compared in Figure 10. Based on these results we found out that at IO performance level, 5-storey with $0.7 \mathrm{C}(\mathrm{ER} / \mathrm{CR}=1.464)$, 7-storey with $1 \mathrm{C}(\mathrm{ER} / \mathrm{CR}=1)$, and 10storey with $1.3 \mathrm{C}(\mathrm{ER} / \mathrm{CR}=2.706)$ had better performance. In this regard, we can say that IO performance of low and high rise buildings can be optimized by decreasing seismic coefficient as $70 \%$, while for mid-rise buildings, no need for change in seismic coefficient proposed by Iranian Standard 2800 in order to have optimum IO performance. For high-rise buildings, seismic coefficient should be increased by $130 \%$ for having the optimum IO performance. 
At LS performance level, 5-storey with $1 \mathrm{C}(\mathrm{ER} / \mathrm{CR}=1)$, 7-storey with 0.85C (ER/CR =1.1010), and 10-storey with $1.3 \mathrm{C}(\mathrm{ER} / \mathrm{CR}=1.1417)$ showed stronger performance, So, we can claim that in low-rise buildings the optimum LS performance can be obtained with the seismic coefficients proposed by Standard 2800 and there is no need for change, but in mid-rise buildings it should be decreased by $85 \%$ while for high-rise buildings the seismic coefficients proposed by Standard 2800 should be increased by $130 \%$ in order to have optimum LS performance.

Moreover, at CP performance level, results reported that 5-storey with $1 \mathrm{C}(\mathrm{ER} / \mathrm{CR}=1)$, 7-storey with $0.7 \mathrm{C}(\mathrm{ER} / \mathrm{CR}$ $=1)$, and 10-storey with $1 \mathrm{C}(\mathrm{ER} / \mathrm{CR}=1)$ showed better performance. In this regard, it can said that low and high-rise buildings require no change in their seismic coefficients proposed by Standard 2800 to have optimum $\mathrm{CP}$ performance, but in mid-rise buildings the proposed seismic coefficient should decreased by $70 \%$.

For calculating ER using real records, we can divide the inter-story drift of specimens into the inter-story drift of modeled structures. ER/CR results of specimens using real records are shown in Figure 11. Based on these results, it was observed that 5 and 7-storey with $0.7 \mathrm{C}$ (ER/CR $=1.3892$ and 1.0691 , respectively) and 10-storey with $0.85 \mathrm{C}$ $(E R / C R=1.1268)$ had better performance against real earthquake records which was almost similar to the results of structures using ET records.

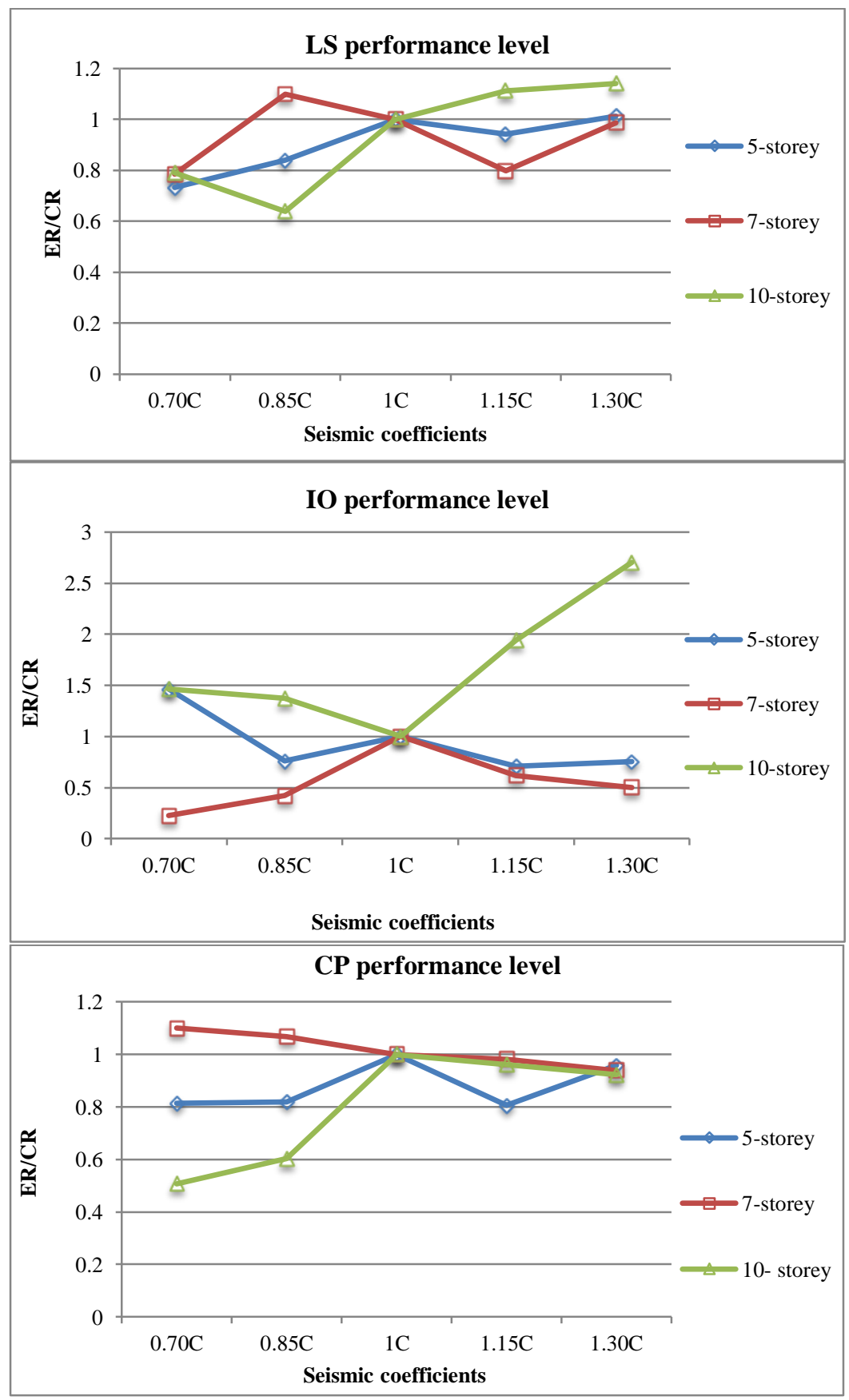

Figure 10. ER/CR results of specimens for three performance levels using ET records 


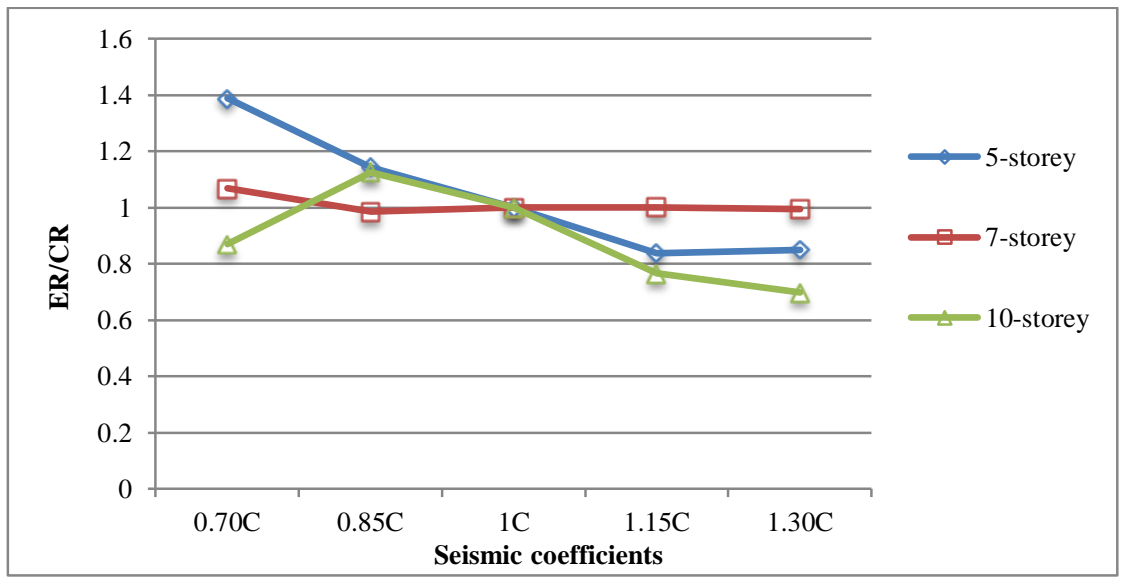

Figure 11. ER/CR results for specimens using real records

\section{Conclusion}

In this study, performance of three concrete special moment frames with 5, 7, and 10 storeys located in Tehran, Iran was assessed by using ET method. The specimens had different base shears, corresponding to different seismic coefficients of $0.7,0.85,1,1.15$, and 1.30 times the proposed values of Iranian Standard 2800. Based on the results, it was found out that: better performance cannot be achieved in low and high-rise buildings by increasing the seismic coefficients, but in mid-rise buildings we can reach better performance against earthquake by the increase of seismic coefficient. Inter-story drift results obtained according to FEMA-356 and considering the importance of CP performance level revealed that by increasing seismic coefficient, only mid-rise buildings could have better performance against earthquake. Based on residual drift, by the increase of seismic coefficient, low and high-rise buildings can perform better than mid-rise buildings. According to the results of ER/CR ratio and considering the importance of CP performance level, optimum structure was a mid-rise structure whose seismic coefficient had been reduced by $70 \%$. In low and high-rise buildings, optimum structure was the one with unchanged seismic coefficient. Random parameters of EA accelerogram can have significant impact on the structure and its damage; so it is necessary to select appropriate EA accelerometers for seismic analysis. Choosing different damage indices for structures in EA method can result in different endurance time for them. The structures that are designed according to the Standard 2800 do not necessarily have the best performance considering the cost (more weight) that has been allocated to them. Moreover, it was observed that the results of ET records and real records were close to each other. We concluded that high safety cannot be achieved simply by increasing the seismic coefficient and the weight of structures. We recommend further studies on concrete special moment frames with irregular plan or on concrete structures with intermediate moment frame. The procedure defined in this study for finding optimum structure can also be used in steel moment frames.

\section{References}

[1] SEAOC "Vision 2000 - A Framework for Performance Based Design, vol. I-III." Los Angeles, California: Seismology Committee, Structural Engineers Association of California, Sacramento, San Francisco. (1995).

[2] Krawinkler, H. and Miranda, E. “Performance-based earthquake engineering”, In Earthquake Engineering: From Engineering Seismology to Performance-Based Engineering, Y. Bozorgnia and V.V. Bertero, Eds., CRC Press, USA (2004). http://thuvienso.hau.edu.vn:8888/dspace/bitstream/hau/4685/13/1439_C13.pdf

[3] Mirzaee,A., Estekanchi, H.E., and Vafai, A. "Improved methodology for endurance time analysis: From time to seismic hazard return period." Scientia Iranica A 19 (2012), 1180-1187. http://dx.doi.org/10.1016/j.scient.2012.06.023

[4] Tavazo, H., Estekanchi, H. E., and Kaldi, P. "Endurance time method in the linear seismic analysis of shell Structures." International Journal of Civil Engineering. 10 (2012): 169-178. http://ijce.iust.ac.ir/article-1-559-en.html

[5] Estekanchi, H. E., Vafai A., and Sadeghazar, M. "Endurance Time method for seismic analysis and design of structures." Scientia Iranica, 11(2004): 361-370. http://scientiairanica.sharif.edu/article_2540_f1bf34a38fb5c8a146f456cef9344f5f.pdf

[6] Estekanchi, H.E., Valamanesh, V. and Vafai, A. "Application of Endurance Time Method in Linear Seismic Analysis." Engineering Structures, 29(2007): 2551-2562. https://doi.org/10.1016/j.engstruct.2007.01.009

[7] Estekanchi, H.E., Riahi, H.T., and Vafai, A. "Application of endurance time method in seismic assessment of steel frames." Engineering Structures, 33(September 2011): 2535-2546. https://doi.org/10.1016/j.engstruct.2011.04.025

[8] Valamanesh, V., and Estekanchi, H.E. " A study of endurance time method in the analysis of elastic moment frames under three-directional seismic loading.” Asian Journal Of Civil Engineering (Building And Housing) 11 (2010): 543-562. 
http://www.sid.ir/En/VEWSSID/J_pdf/103820100501.pdf

[9] Riahi, H.T., Estekanchi, H.E., and Seyedain Boroujenia, S. " Application of Endurance Time Method in Nonlinear Seismic Analysis of Steel Frames.” Procedia Engineering, 14 (2011): 3237-324. https://doi.org/10.1016/j.proeng.2011.07.409

[10] Alembagheri M., and Estekanchi, H.E. "Seismic assessment of unanchored steel storage tanks by endurance time method." Earthquake Engineering And Engineering Vibration, 10(2011): 591-604. https://doi.org/10.1007/s11803-011-0092-y

[11] Valamanesh, V., Estekanchi, H.E., Vafai, A., and Ghaemian, M. "Application of the endurance time method in seismic analysis of concrete gravity dams.” Scientia Iranica, 18(June 2011): 326-337. https://doi.org/10.1016/j.scient.2011.05.039

[12] Basim, M.C., and Estekanchi, H.E. “Application of ET method in value-based seismic design of structures.” Second European conference on earthquake engineering and seismology. Istanbul, Turkey (2014).

[13] Amouzegar,H., and Tajmir Riahi, H. "Seismic assessment of concrete frames by endurance time method." Proceedings of the Institution of Civil Engineers - Structures and Buildings, 168(August 2015): 578-592. https://doi.org/10.1680/stbu1400042

[14] Maleki-Amin, M.J., andEstekanchi, H.E. "Application of damage spectra as seismic intensity measures in endurance time method for steel moment-resisting frames.” Scientia Iranica A 24(2017): 53-64. https://doi.org/10.24200/sci.2017.2376

[15] Takeda, T., Sozen, M.A. and Nielsen, N.N. "Reinforced Concrete Response to Simulated Earthquake." Journal of Structural Division, 96 (1970): 2557-2573. http://cedb.asce.org/CEDBsearch/record.jsp?dockey=0017038

[16] Federal Emergency Management Agency. "Improvement of Nonlinear Static Seismic Analysis Procedure" FEMA-440. Washington, DC. (2005).

[17] Federal Emergency Management Agency. "Prestandard and Commentary for Seismic Rehabilitation of Buildings." FEMA-356, Washington, DC.(2000). 